\title{
COMMENTS ON DISLOCATION VELOCITY AND \\ MACRO-DEFORMATION IN MOLYBDENUM
}

\author{
T. Vreeland, Jr. and A. P. L. Turner \\ W. M. Keck Laboratory of Engineering Materials \\ California Institute of Technology \\ Pasadena, California
}

This note presents several comments on the paper "Dislocation Velocity Measurements in High Purity Molybdenum" by Prekel, Lawley, and Conrad ${ }^{1}$ (PLC). PLC concluded from their result "that plastic deformation of molybdenum is controlled by the thermally assisted overcoming of the Peierls-Nabarro hills by the double kink mechanism proposed by Seeger, at least in the stress ranges that were examined". Further PLC suggest that "the same mechanism is operative during micro - and macro straining", and "the equivalence of experimental data from strain rate change experiments and dislocation velocity measurements also substantiates the usual assumption that the mobile dislocation density and long range internal stress field remain constant during a strain rate change."

PLC point out the agreement between the observed stress exponent, $m$, and the predictions of the Peierls-Nabarro model of Seeger ${ }^{2}$ with regard to the temperature dependence. Stein ${ }^{3}$ has compared the PLC data with the predictions of the Peier1s-Nabarro model of Dorn and Rajnak ${ }^{4}$ and reports "extreme disagreement between the temperature dependence of dislocation mobility and the prediction made by the Peierls-Nabarro mechanism." We find by a critical examination of the PLC dislocation velocity data that the Seeger model does not apply. Further, a comparison of the dislocation velocity data with the strain rate change experiments indicates that different mechanisms are operative in the micro and in the macro strain regions. The dislocation velocity vs stress data of PLC at $77^{\circ} \mathrm{K}$ and $300^{\circ} \mathrm{K}$ may be analyzed to give a) the Peierls-Nabarro stress, $\tau_{p}^{o}$, which appears in the Seeger model, and b) the acti- 
vation energy, $\Delta H$, in any model which predicts a velocity, $v=v_{0} \exp (\Delta H / k T)$. We obtain

$$
\begin{aligned}
\tau_{\mathrm{p}}^{0} & =2.3 \times 10^{-2} \mathrm{~kg} / \mathrm{mm}^{2}, \text { and } \\
\Delta H & =0.26 \mathrm{eV}\left(\text { at } 1 \mathrm{~kg} / \mathrm{mm}^{2}\right)
\end{aligned}
$$

Since the predicted Peierls stress is less than the applied stresses in the experimental work $\left(1-7 \mathrm{~kg} / \mathrm{mm}^{2}\right.$ ) the model (in the form used by PLC) should not apply, and therefore the data cannot support the model.

An activation energy $\Delta H=1.57 \mathrm{eV}$ (at $1 \mathrm{~kg} / \mathrm{mm}^{2}$ ) was found by Conrad and Hayes ${ }^{5}$ in the strain rate change experiments on polycrystalline molybdenum. As this activation energy for macro deformation differs by a factor of about 6 from that for the micro deformation, it would appear that different mechanisms are operative.

We therefore conclude that:

1. The PLC dislocation velocity data in molybdenum are not consistent with the Seeger formulation of the thermally assisted overcoming of the Peierls-Nabarro hills by the double kink mechanism².

2. The difference in activation energies clearly illustrates that the strain rate relationship in B.C.C. materials is not independent of strain.

\section{$\underline{\text { References }}$}

1. H. L. Preke1, A. Lawley, and H. Conrad, Acta Met. 16, 337, (1968).

2. A. Seeger, Phil. Mag. 1, 651 (1956).

3. D. F. Stein, Scripta Met. 2, 555 (1968).

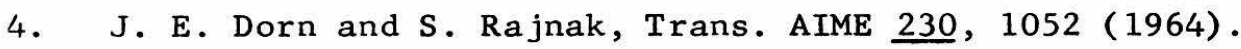

5. H. Conrad and W. Hayes, Trans. ASM $\underline{56}, 249$ (1963). 